\title{
Color singleton pop-out does not always poop out: An alternative to visual search
}

\author{
WILLIAM PRINZMETAL and NADIA TAYLOR \\ University of California, Berkeley, California
}

\begin{abstract}
Folk psychology suggests that when an observer views a scene, a unique item will stand out and draw attention to itself. This belief stands in contrast to numerous studies in visual search that have found that a unique target item (e.g., a unique color) is not identified more quickly than a nonunique target. We hypothesized that this finding is the result of task demands of visual search, and that when the task does not involve visual search, uniqueness will pop out. We tested this hypothesis in a task in which observers were presented an array of letters and asked to respond aloud, as quickly as possible, with the identity of any one of the letters. The observers were significantly more likely to respond with a uniquely colored letter than would be expected by chance. In a task in which observers blurt out the first thing that they see, unique pop-out does not poop out.
\end{abstract}

Imagine the following scenario. It's a football weekend in Berkeley, California, and you are planning to meet your friend at a popular restaurant. Your friend thinks that because the restaurant is going to be crowded, you might have trouble finding her. She expects that most people will be wearing Cal Berkeley colors (blue and gold), and, unbeknownst to you, decides that if she wears an odd color (red) she will stand out and be easier to find. Folk knowledge suggests that objects with odd or unique features stand out, and that it might be easier to find a person wearing an odd color, even if the searcher is not particularly looking for an odd color.

Surprisingly, there is a plethora of research using visual search that demonstrates that observers are not faster in finding a uniquely colored target if being unique is not associated with the target (see, e.g., Jonides \& Yantis, 1988; Theeuwes, 1990; Yantis \& Egeth, 1999). For example, Jonides and Yantis (1988) had observers search for a target letter among seven letters. One of the letters was uniquely colored (e.g., red among green items). On 1/7 of the trials, the target was the uniquely colored letter, and on the remaining trials, a nontarget was uniquely colored. The observers were not faster at finding the target when it was uniquely colored. We term the failure of uniqueness to affect reaction time (RT) in visual search pop-out poop$o u t$. This situation differs from the task in which being unique, per se, is associated with being the target (see, e.g., Bacon \& Egeth, 1994; Theeuwes, 1990, 1992). However, if uniqueness is not associated with being the target, the presence of a unique item does not affect search RT.

\footnotetext{
We thank Emily Miller and Ramona Rostami for their help in data collection. We also thank Ayelet Landau and Natalie Merchant for their helpful comments on the manuscript. Correspondence concerning this article should be sent to W. Prinzmetal, Department of Psychology, University of California, Berkeley, CA 94720-1650 (e-mail: wprinz@ berkeley.edu).
}

Pop-out poop-out in visual search is an extremely robust noneffect. It not only occurs with unique color, but also with singletons of motion (Hillstrom \& Yantis, 1994; Yantis \& Egeth, 1999), shape (Theeuwes, 1990), and other attributes (for a review, see Yantis, 1993).

Perhaps because pop-out poop-out in visual search is nonintuitive and counter to folk psychology, researchers have sought out exceptions, and two classes of exceptions have been found. The first exception is when the uniqueness breaks camouflage, in which case RT is decreased when the target is the unique item (see, e.g., Hillstrom \& Yantis, 1994; Todd \& Kramer, 1994). The second exception is a sudden change in a stimulus property that makes the target unique. The change can be the sudden appearance of a new object (Yantis \& Jonides, 1984, 1990), the sudden onset of motion (Abrams \& Christ, 2003; Franconeri \& Simons, 2003), or a sudden change in color or luminance (Franconeri, Simons, \& Junge, 2004; von Mühlenen, Rempel, \& Enns, 2005). If the target is in the location of the sudden change, responses are faster than when the target is in another location. Although the sudden onset of motion might be a naturally occurring event (e.g., my friend might wave her hand to get my attention), other changes would seem less natural - for example, if my friend suddenly appeared where no person had been before, or her clothes suddenly changed color. ${ }^{1}$

The present research is not concerned with finding an additional exception to pop-out poop-out in visual search. Rather, we were interested in accounting for the folk belief that oddly colored items stand out, whereas in visual search, a uniquely colored target is not found faster when uniqueness is not associated with being the target. We hypothesized that the reason pop-out poop-out occurs is that visual search is a goal-directed activity, and in pop-out poop-out, uniqueness is not related to the goal. In visual search, there is always a specific target, or several different targets, among distractors. The observer decides 
whether the target is present or, in the case of multiple targets, which target is present. Perhaps if the task were not visual search, uniquely colored items would be responded to preferentially. Many activities outside the laboratory do not involve searching for a specific target.

Two lines of evidence motivated this hypothesis. The first line of evidence comes from the Internet technology literature and the phenomenon of "banner blindness" (Benway \& Lane, 1998). Benway and Lane gave subjects Internet search tasks such as "find the e-mail address of the Neemrana Hotel." For one group, the task could be completed by following a link in the Web site banner (e.g., "New! Neemrana Hotels"). For the other group, the task could be completed by following a link in the body of the Web page. The subjects were almost twice as likely to succeed in the search when the search target could be found by following a link in the body of the Web page rather than in the banner. Banner blindness is relevant to stimulus-driven capture because banners are often unique in color or are unique in that they are dynamic, whereas the rest of a Web page is more often static and homogeneous in color.

Pagendarm and Schaumburg (2001) tested the hypothesis that banner blindness was due to the fact that when searching for a specific piece of information, subjects know that banners tend to provide no useful information. Pagendarm and Schaumburg ran two groups of subjects. One group engaged in a search task. The other group was simply directed to engage in "aimless browsing." Both groups were then given memory tests on information contained in the banners. The aimless browsing group had significantly higher recall and recognition of the banners than the goal-directed search group. Thus, when in search mode, we intentionally avoid the "unique items" (the banners), but we look at them when not engaged in goaldirected search (i.e., aimless browsing). This study indicates that our interactions with unique items are strongly influenced by our goals.

The second line of evidence that led us to the belief that pop-out poop-out might be related to visual search was a study by Pashler and Harris (2001). Each observer participated in a single trial. The observers were told to watch a single presentation of a stimulus. After the presentation, they were asked to describe what they saw. The stimuli consisted of six words presented for $900 \mathrm{msec}$, under two conditions. In the first condition, one of the words was blinking rapidly and the others were static, and in the second condition, one of the words was static and the others were blinking. Pashler and Harris found that the observers were more likely to report a unique item (whether blinking or not), as well as blinking items (whether unique or not). They concluded that they did not find pop-out poop-out because the observers were not engaged in a goal-directed search task. However, they did not run a standard search task as a control, so we do not know whether they would have obtained pop-out poop-out in visual search.

The goal of the present research was to develop an alternative to visual search and test whether uniquely colored items are processed differently, as suggested by folk psychology. In developing our method, we wanted to generalize this previous work in a multiple-trial procedure. Furthermore, we wanted a situation that had few demands on memory. Finally, we wanted to make it possible to control eye movements. It is possible that a unique or flashing banner attracts eye movements, and observers remember what they fixate.

In our alternative to visual search, the observers were presented a display that consisted of five letters, randomly selected from the alphabet (without replacement, Figure 1). The task was to verbally blurt out the first letter they saw. The experimenter entered the responses on a keyboard, and RTs were obtained with a voice-operated relay. A response of any of the five display letters was correct, and a response of any nondisplayed character was an error. On some of the displays, four of the letters were one color and one was unique in color. In the blurt-out task, we hypothesized that the observers would respond with the odd-colored item more than would be expected by chance.

In the first experiment, a typical visual search task was used in order to establish that we had a pop-out poop-out situation. The remaining experiments used our "blurt-out" method. The display parameters were similar in all of the experiments, and the observers always responded verbally.

\section{GENERAL METHOD}

\section{Subjects}

Twelve subjects participated in each experiment. In Experiments 2 and 4, 1 subject was replaced, as described below. All of the subjects were recruited from the University of California, Berkeley, and received course credit for their participation.

\section{Apparatus and Stimulus \\ The stimulus presentation was controlled by a Macintosh G3 computer and was presented on a 15-in. multiscan Apple monitor set}

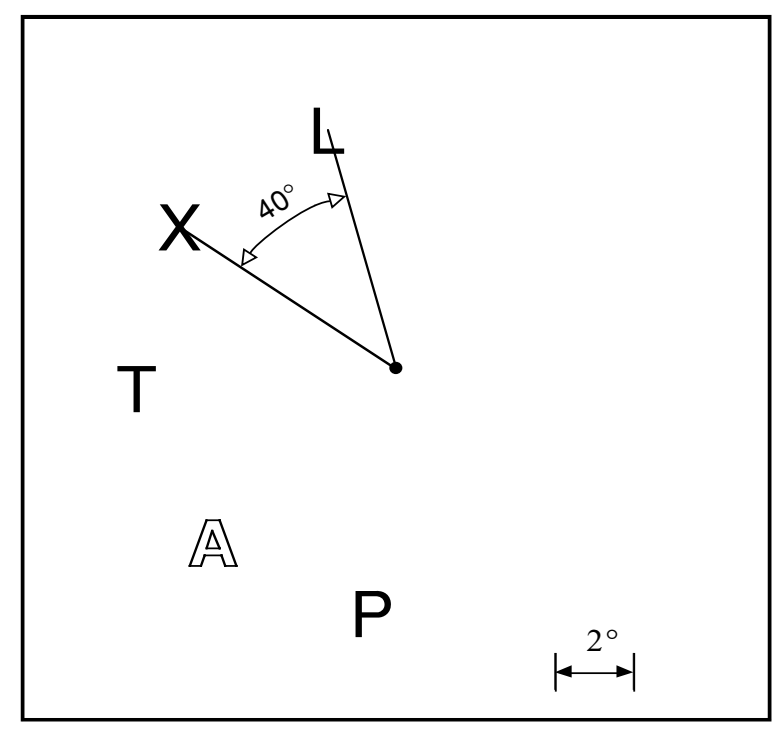

Figure 1. The near eccentricity, $40^{\circ}$ spacing condition is illustrated. One letter (outlined typeface) was one color, and the remaining letters another. The figure is drawn to scale. 
at $832 \times 624$ pixels at $75 \mathrm{~Hz}^{2}{ }^{2}$ The subjects' heads were restrained with a chinrest, and a microphone was positioned immediately in front of them. The viewing distance was $43 \mathrm{~cm}$.

A sample stimulus is shown in Figure 1. The outlined letter was one color (red or blue) and the solid letters were the other color. The background was white. The letters were located on an imaginary circle whose radius subtended either $6.5^{\circ}$ or $11.1^{\circ}$. The spacing between the letters on the imaginary circle was either $30^{\circ}$ or $40^{\circ}$ of arc (Figure 1). The location of the five letters on the circle was randomly determined.

On trials in which there was an odd-colored letter (see below), the odd color was equally often red and blue. The red and blue were approximately equal in brightness. The odd-colored letter occurred equally often in each position of the string.

\section{Procedure}

The general procedure was as follows, except as noted in individual experiments. A fixation point was visible throughout a block of trials. The stimulus was presented for $200 \mathrm{msec}$. The observers responded orally, which terminated a clock. The experimenter then entered the subject's response with the keyboard. The next trial began $1.5 \mathrm{sec}$ after the response was entered. In Experiment 4, the stimulus remained in view until the subject responded. In all of the experiments, when subjects erred, the computer emitted a brief "beep" sound. After approximately 10 practice trials, data were collected on four blocks of 80 trials. The order of stimuli within a block was random. The experiment took between 30 and $45 \mathrm{~min}$.

\section{EXPERIMENT 1}

Experiment 1 was a visual search task. Each display contained a target letter: either $\mathrm{X}$ or $\mathrm{O}$. The remaining four letters were randomly selected from the alphabet. The target letter occurred equally often in each position of the string. In each trial, one letter was an odd color. The target letter was the uniquely colored letter on $1 / 5$ of the trials. Thus, being an odd color was uncorrelated with being the target. The subjects responded verbally, "X" or "O."

The observers were $94.3 \%$ correct, and analysis included only correct RTs. RTs shorter than $100 \mathrm{msec}$ and longer than 2,000 msec were excluded from analysis $(0.9 \%$ of trials $)$. The average RT when the target was a unique color was $506 \mathrm{msec}$, compared with $512 \mathrm{msec}$ when the target color was not unique. This difference was not reliable $[F(1.11)=0.39]$.

There was an interaction between eccentricity and uniqueness of the target $[F(1,11)=9.83, p<.05]$. With the near eccentricity, the observers were faster when the target was the odd-colored letter, 459 versus $471 \mathrm{msec}$. However, this difference was not reliable $[t(11)=1.40, p=.09$ (onetailed)]. Though not significant, this tendency may be an example of pop-out due to breaking camouflage.

At the far eccentricity, the observers were significantly slower when the target was the odd color, 519 versus $497 \mathrm{msec}[t(11)=2.25, p<.05]$. This may have occurred because observers first searched the nonunique items and then the unique item. Whatever the cause of this effect, in the following experiments, which do not use visual search, the far eccentricity condition will be the critical condition, since these displays very clearly exhibited pop-out poop-out.

\section{EXPERIMENT 2}

Having established pop-out poop-out with our stimuli, we began to investigate whether another nonsearch task would show unique pop-out. The observers' task was to blurt out the first letter they saw. Any of the five display letters would be a correct response. Display items were selected randomly from the alphabet. ${ }^{3}$

We determined the percentage of trials on which the observers responded with the odd-colored letter. In this analysis, we excluded errors (4\% of the trials). One observer had a bias to nearly always respond with the oddcolored letter (98\%). Because this observer's data were so extremely different from those of the other observers, we replaced the observer.

The subjects in Experiment 2 showed a bias to respond with the odd-colored letter more than would be expected by chance. By chance, one would expect observers to respond with the odd-colored letter on $20 \%$ of the trials. The observers responded with the odd-colored letter on an average of $27.3 \%$ of trials (range, $19.6 \%-35.7 \%$ ). ${ }^{4}$ The bias was significantly different from the expected $20 \%$ $[t(11)=3.65, p<.01]$. Critically, the bias was significantly higher than $20 \%$ for the far eccentricity condition $[25.4 \% ; t(11)=2.74, p<.01]$. In the visual search task, this condition had no sign of pop-out. The bias was also significantly higher than would be expected by chance for the near eccentricity condition $[29.0 \% ; t(11)=3.74$, $p<.01]$.

Although the observers were more likely to blurt out the odd-colored letter, they did not respond faster on trials in which they did so. RTs for responses with the odd-colored letter and the non-odd-colored letters were $478 \mathrm{msec}$ and $481 \mathrm{msec}$, respectively $[F(1,11)=0.16]$. The only significant effect in the analysis of RT was the effect of eccentricity. The observers were faster on the near eccentricity displays than the far eccentricity displays, $474 \mathrm{msec}$ versus $491 \mathrm{msec}[F(1,11)=7.13, p<.05]$.

In summary, in all of the conditions, the observers were more likely to respond with the odd-colored letter. This finding included a condition in which observers were actually slower to respond to a uniquely colored target in the visual search task (i.e., Experiment 1).

\section{EXPERIMENT 3}

In Experiment 2, the observers were more likely to respond with the odd-colored letter. We were worried, however, that this result might have been influenced by the obvious nature of the stimuli: Every trial contained one oddly colored letter. This fact may have set up an implicit expectation for the observers to respond with the oddcolored letter. Thus, in Experiment 3, we added filler trials. On $50 \%$ of the trials, two randomly selected letters were one color and three the other. These filler trials were not analyzed. The number of trials per block was doubled 
to accommodate the filler trials, and data were collected over six blocks.

The results were nearly identical to those of Experiment 2 . The observers responded with the uniquely colored item on $27.2 \%$ of the trials (range, $19.7 \%-56.4 \%$ ). This bias was significantly different than would be expected by chance - that is, $20 \%[t(11)=2.58, p<.05]$. The effect was as large for the far eccentricity condition $[27.1 \% ; t(11)=2.61, p<.05]$ as the near eccentricity condition $[27.6 \% ; t(11)=2.44, p<.05]$. Thus, adding the filler trials did not diminish the bias to report the uniquely colored item.

As in the previous experiment, the observers were not significantly faster when responding with the uniquely colored item. The RTs for the unique and nonunique item responses were 476 and $442 \mathrm{msec}$, respectively $[F(1,11)=0.88]$. As in Experiment 2, the observers were faster for the near than the far eccentricity, $442 \mathrm{msec}$ versus $461 \mathrm{msec}[F(1,11)=13.79, p<.01]$. Unlike with the other experiments reported here, there was an effect of spacing: The observers were faster with the far spacing $\left(40^{\circ}\right.$, see Figure 1) than the near spacing $\left(30^{\circ}\right), 441 \mathrm{msec}$ versus $461 \mathrm{msec}[F(1,11)=7.9, p<.01]$. This effect was probably due to lateral masking. There were no other significant effects or interactions.

\section{EXPERIMENT 4}

In Experiments 2 and 3, the observers were more likely to blurt out the oddly colored item. Although the memory requirements were less than they were in Pashler and Harris (2001) - in which observers were instructed to report everything that they saw-in Experiments 2 and 3,observers did have to remember one item until they could report it. To eliminate any necessity of relying on memory, in Experiment 4, the stimuli remained in view until the observer responded. We monitored eye movements with a video camera, and when observers moved their eyes, the computer said "Eye Movement." Details of the eyemovement apparatus are given in Prinzmetal, McCool, and Park (2005). These trials $(<1 \%)$ were eliminated from analysis, as were errors $(4.0 \%)$. In other respects, the experiment was identical to Experiment 2.

One observer responded with the odd-colored item on an excessive percentage of trials (98\%), and was replaced. The remaining observers reported the odd-colored item on an average of $25.2 \%$ of trials (range, $21.2 \%-27.5 \%$ ). Each of the observers responded with the odd-colored letter on more than $20 \%$ of the trials. This effect was significantly greater than would be expected by chance for both the far eccentricity condition $[25.3 \% ; t(11)=3.08, p<.01]$ and the near condition $[25.1 \% ; t(11)=3.27, p<.01]$. Thus, when we took away any memory demands by having the stimuli remain in view until the observers responded, and we monitored eye movements, the observers were still more likely to respond with the odd-colored letter.

The only factor that significantly affected RT was eccentricity. The observers were significantly faster with the near than the far eccentricity condition, $620 \mathrm{msec}$ ver- sus $658 \mathrm{msec}[F(1,11)=10.70, p<.01]$. The observers did not respond faster when they reported the uniquely colored letter. The average RTs for reporting unique and nonunique items were 645 and $633 \mathrm{msec}$, respectively $[F(1,11)=2.49$, n.s. $]$. There were no other significant effects or interactions.

\section{DISCUSSION}

Previous investigators using visual search have found that observers were not faster in finding a unique target, except if the unique attribute involved a sudden change in that attribute or breaking of camouflage. In Experiment 1 , we replicated the finding that a uniquely colored item does not "pop out" in visual search. When uniqueness is unrelated to the target of the visual search, it is ignored. In the remaining experiments, the observer's task was not to search for a target, but merely to blurt out the first letter they perceived. The observers responded with the uniquely colored letter more often than would be expected by chance. Over the three "blurt-out" experiments, 36 out of 38 observers were more likely to respond with the uniquely colored item than would be expected by chance. Our results complement the findings of Pashler and Harris (2001), who used a single-trial procedure. Regardless of whether observers were to report "everything they saw," with a single trial (i.e., Pashler \& Harris), or the first letter they saw, in a multitrial procedure, the unique color did pop out when the observers were not engaged in visual search.

Although one might find pop-out in visual search in some circumstances, the present studies demonstrate that one is more likely to find unique pop-out in a task that does not require visual search than in one that does. Using the same stimuli with which we did not find pop-out in visual search, we found that a uniquely colored item did receive processing priority when the observers were not engaged in goal-directed search.

A central question is: What type of processing priority is the unique item receiving? There are at least two possibilities. First, perceptual resources might be attracted to the unique item so that it is processed more quickly and completely than other items (see, e.g., Prinzmetal, 2005). Presently, we do not favor this hypothesis, because although the observers were more likely to report the unique item, they were not faster in doing so.

A second possibility is that uniqueness affects what Allport (1989) called "selection for action." That is, it involves a quick decision about which stimulus the organism should respond to (Prinzmetal, McCool \& Park, 2005; Prinzmetal, Park, \& Garrett, 2005). The issue of how selection affects processing permeates the literature on stimulus-driven capture (Rauschenberger, 2003). Even under conditions that lead to pop-out in visual search, we do not know the mechanism of "capture."

Although we do not know the mechanism whereby a uniquely colored item receives priority in processing, we can speculate on the analogue of search and blurt-out tasks in everyday activities. Consider the task introduced at the 
beginning of this article: You are searching for a friend in a crowded restaurant. The question that we asked is whether your friend would be found faster if she wore a unique color (e.g., red in a sea of blue). The answer from previous research is that you would not necessarily find her faster unless you were looking for an odd color. If, on the other hand, other patrons were in "browser mode," they would more likely notice her if she wore red in a sea of blue. ${ }^{5}$

\section{REFERENCES}

Abrams, R. A., \& Christ, S. E. (2003). Motion onset captures attention. Psychological Science, 14, 427-432.

Allport, A. (1989). Visual attention. In M. I. Posner (Ed.), Foundations of cognitive science (pp. 631-682). Cambridge, MA: MIT Press.

BACON, W. F., \& EgETH, H. E. (1994). Overriding stimulus-driven attentional capture. Perception \& Psychophysics, 55, 485-496.

Benway, J. P., \& Lane, D. M. (1998, December). Banner blindness: Web searchers often miss "obvious" links. Internetworking, 1(3). Retrieved September 11, 2006, from www.internettg.org/newsletter /dec98/banner_blindness.html.

Franconeri, S. L., \& Simons, D. J. (2003). Moving and looming stimuli capture attention. Perception \& Psychophysics, 65, 999-1010.

Franconeri, S. L., Simons, D. J., \& Junge, J. A. (2004). Searching for stimulus-driven shifts of attention. Psychonomic Bulletin \& Review, 11, 876-881.

Hillstrom, A. P., \& Yantis, S. (1994). Visual motion and attentional capture. Perception \& Psychophysics, 55, 399-411.

JONIDES, J., \& YANTIS, S. (1988). Uniqueness of abrupt visual onset in capturing attention. Perception \& Psychophysics, 43, 346-354.

Pagendarm, M., \& Schaumburg, H. (2001, August 24). Why are users banner-blind? The impact of navigation style on the perception of Web banners. Journal of Digital Information, Article No. 47, 2(1). Retrieved September 11, 2006, from http://jodi.tamu.edu/Articles /v02/i01/Pagendarm.

Pashler, H., \& Harris, C. R. (2001). Spontaneous allocation of visual attention: Dominant role of uniqueness. Psychonomic Bulletin \& Review, 8, 747-752.

Prinzmetal, W. (2005). Location perception: The X-Files parable. Perception \& Psychophysics, 67, 48-71.

Prinzmetal, W., McCool, C., \& Park, S. (2005). Attention: Reaction time and accuracy reveal different mechanisms. Journal of Experimental Psychology: General, 134, 73-92.

Prinzmetal, W., Park, S., \& Garrett, R. (2005). Involuntary attention and identification accuracy. Perception \& Psychophysics, 67, 13441353.

RAuSCHENBERger, R. (2003). Attentional capture by auto- and allocues. Psychonomic Bulletin \& Review, 10, 814-842.
ShiU, L., \& PASHLER, H. (1994). Negligible effect of spatial precuing on identification of single digits. Journal of Experimental Psychology: Human Perception \& Performance, 20, 1037-1054.

Theeuwes, J. (1990). Perceptual selectivity is task dependent: Evidence from selective search. Acta Psychologica, 74, 81-99.

Theeuwes, J. (1992). Perceptual selectivity for color and form. Perception \& Psychophysics, 51, 599-606.

TodD, S., \& Kramer, A. F. (1994). Attentional misguidance in visual search. Perception \& Psychophysics, 56, 198-210.

Turatto, M., Galfano, G., Gardini, S., \& Mascetti, G. G. (2004). Stimulus-driven attentional capture: An empirical comparison of display-size and distance methods. Quarterly Journal of Experimental Psychology, 57A, 297-324.

von Mühlenen, A., Rempel, M. I., \& EnNS, J. T. (2005). Unique temporal change is the key to attentional capture. Psychological Science, 16, 979-986.

Yantis, S. (1993). Stimulus-driven attentional capture. Current Directions in Psychological Science, 2, 156-161.

Yantis, S., \& EgETH, H. E. (1999). On the distinction between visual salience and stimulus-driven attentional capture. Journal of Experimental Psychology: Human Perception \& Performance, 25, 661-676.

YAnTIS, S., \& Jonides, J. (1984). Abrupt visual onsets and selective attention: Evidence from visual search. Journal of Experimental Psychology: Human Perception \& Performance, 10, 601-621.

Yantis, S., \& Jonides, J. (1990). Abrupt visual onsets and selective attention: Voluntary versus automatic allocation. Journal of Experimental Psychology: Human Perception \& Performance, 16, 121-134.

\section{NOTES}

1. A third class of exception includes a few RT experiments with extremely high error rates, as high as $40 \%$ (see, e.g., Turatto, Galfano, Gardini, \& Mascetti, 2004). Under these circumstances, the results probably should be attributed to location uncertainty. Subjects simply did not know which location contained the target, but they based their responses on the odd-colored location (see Shiu \& Pashler, 1994).

2. The computer software for running these experiments will be made available at www.psychonomic.org/archive/.

3. For technical reasons, the letter $\mathrm{G}$ was excluded.

4. The effect size (Cohen's $d$ ) $=1.05$, which is larger than many typical RT effects in the literature (e.g., Prinzmetal, McCool, \& Park, 2005).

5. Because the archrival of the University of California, Berkeley, is Stanford University, whose colors are red and white, we do not recommend performing this experiment.

(Manuscript received July 16, 2005; revision accepted for publication January 9, 2006.) 